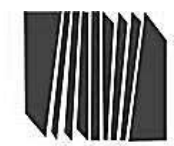

UNIVCRSIDAD PEDAGOGICA EXPLRIIACNTAL LIDERTAOOR

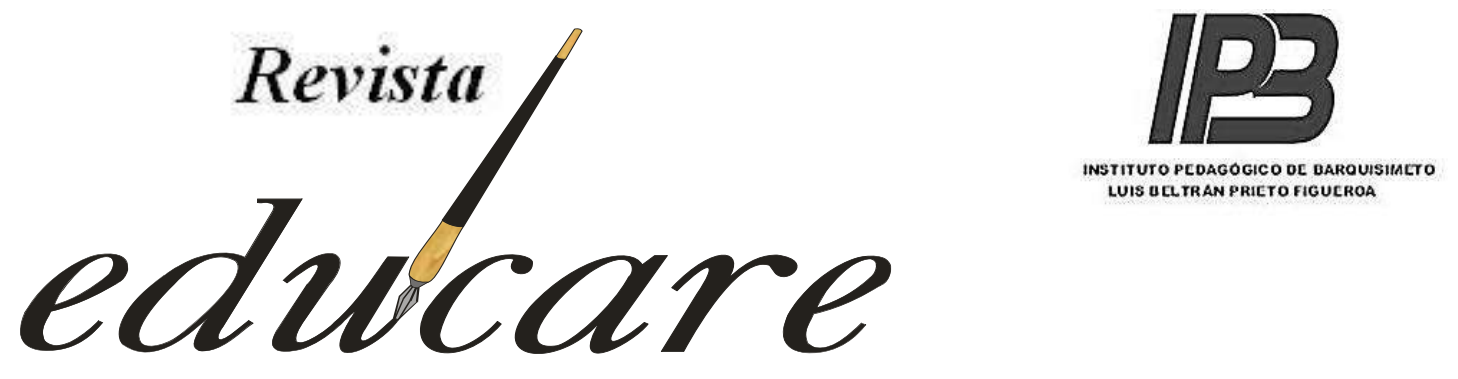

Órgano Divulgativo de la Subdirección de Investigación y Postgrado del Instituto Pedagógico de Barquisimeto "Luis Beltrán Prieto

Figueroa"

BARQUISUUEIO - EDO. LARA - VENEZUEA

\title{
ANALYZING RECAST AS ORAL NEGATIVE FEEDBACK
}

UN ANÁLISIS A LA REFORMULACIÓN COMO RETROALIMENTACIÓN NEGATIVA ORAL

\section{Bexi Perdomo}

\section{Universidad de Los Andes, Venezuela}

(ULA) 


\begin{tabular}{|c|c|}
\hline Trabajo de Investigación & Bexi Perdomo* \\
\hline Recibido:23 -02-2016 & Aceptado: 16-09-2016 \\
\hline ABSTRACT & RESUMEN \\
\hline $\begin{array}{l}\text { Recast has beenfound to be one of } \\
\text { themostfrequentlyused oral feedbacktypes in } \\
\text { second and foreignlanguageclassrooms; } \\
\text { thatexplainswhyit has beenthefocus of studyby } \\
\text { a significantnumber of researchers. The } \\
\text { presentresearchaimedtoanalyzerecast } \\
\text { negative feedback as } \\
\text { theforeignlanguageclassroom. } \\
\text { uniqueconceptofrecastisnotprovidedbutthemai } \\
\text { ndefinitionsresearchershaveproposedthroughy } \\
\text { ears for thistypeof negative feedback are } \\
\text { offeredto help readerstoget } \\
\text { betterunderstandingonthetopic. } \\
\text { Severaltypesofrecast are presentedand some } \\
\text { issuesrelatedto its effectivenessareanalyzed. It } \\
\text { isconcludedthatstudiesregardingrecastseffectiv } \\
\text { enessshouldbecarefullyreviewed in } \\
\text { ordertoidentifypossible bias } \\
\text { duetorecastsambiguityandvariableslikestudents } \\
\text { proficiencyand age, students' } \\
\text { affectivefactors, amongother. } \\
\text { Keywords: implicitnegativefeedback, } \\
\text { foreignlanguageteaching, error treatment }\end{array}$ & 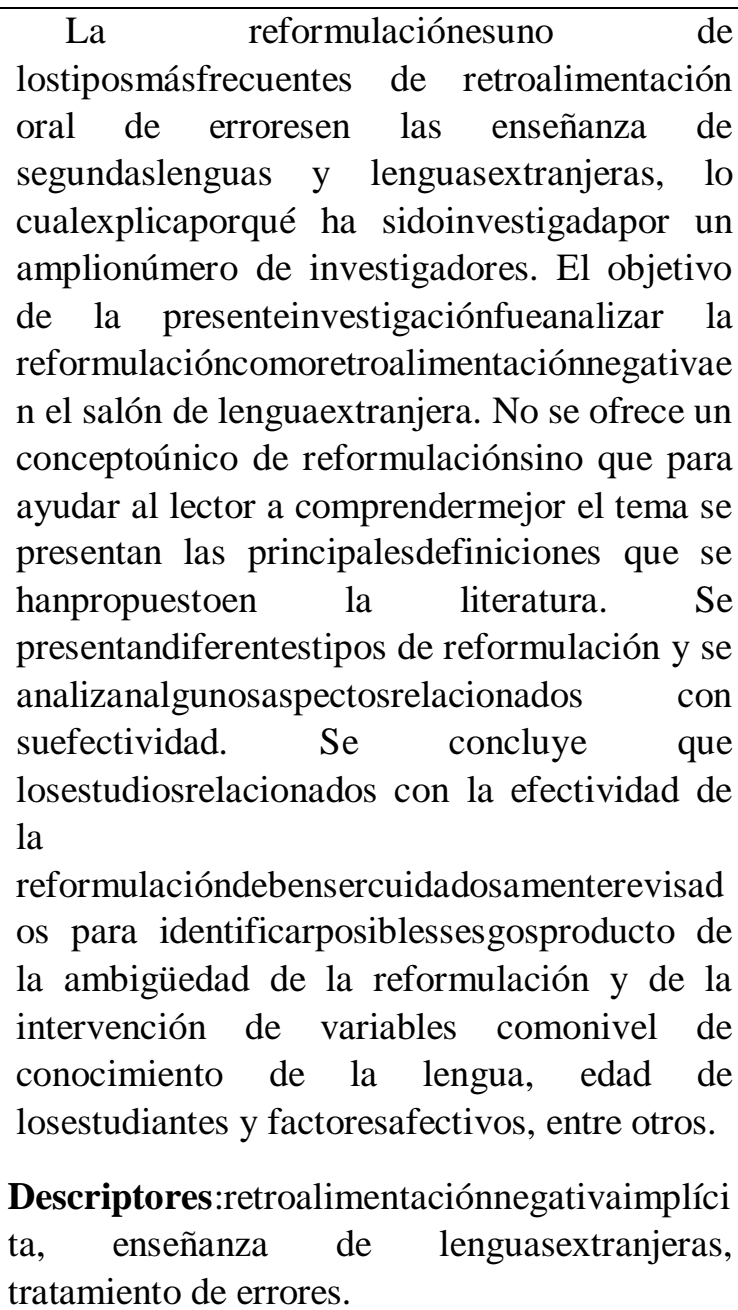 \\
\hline
\end{tabular}

*Lic. En Educación, Mención Inglés y MSC en Educación, Mención Enseñanza de Inglés como Lengua Extranjera. Ha realizado diferentes cursos de postgrado no conducente a título en las áreas de EducaciónSuperior y Lingüística Aplicada. Actualmente es Profesora del Dpto. de Investigación de la Facultad deOdontología de la ULA. Miembro y Administradora del Grupo Multidisciplinario de Investigaciones enOdontología (G-MIO). Correo electrónico: bexi@ula.ve 


\section{INTRODUCTION}

Some authors have indicated, since the early times of Negative Feedback (NF) research, how complex the study of error and error treatment in the FL classroom might be. The main argument is that error treatment is quite far from precise; it is inconsistent and ambiguous, maybe because of the different kinds and the various purposes of the speaking tasks and what teachers mean with the interactional activities.

Research in the field has shown that there are several ways teachers react and respond to students' errors. Among the possibilities for error treatment, recast has been accepted by those who perceive language learning and teaching as a communicative process where the error is seen as a part of the learning and acquisition process of a language, even when it has been hardly criticized by others.

One of the reasons why recast has been the focus of study by a significant amount of researchers is that it has been found to be one of the most frequently used oral feedback types in L2 classrooms for years (Lyster\&Ranta, 1997; Panova\&Lyster, 2002; Sheen, 2006 and Rassaei, Moinzadeh\&Youhannaee, 2012). In this sense, the study of its effectiveness has become mandatory in order to test those conditions in which it might lead to learning. Besides, the study of recast, according to Ellis and Sheen (2006, p. 577), serves as a mean for the investigation of two issues of general theoretical importance in the field of language learning and acquisition: (1) the role of positive and negative evidence in SLA, and (2) the relative impact of implicit and explicit types of NF.

Recast has gained researchers increasing attention; yet, empirical studies have resulted in controversial findings. That controversy restrains the possibilities for a conclusion about recast effectiveness and opens the path for more research to fill the remaining gaps. Further, there are other questions regarding recast still unsolved. For example, although there is evidence that recasts affording just positive evidence can facilitate acquisition, it remains possible (but not yet demonstrated) that recasts that supply both positive and negative evidence are even more effective (Farroky\& Hassan, 2012, p. 73).

The literature shows that there have been problems for providing a unified definition of recast. Rassaei, Moinzadeh\&Youhannaee, 2012b (p. 101) suggest that "Researchers have 
failed to reach a consensus regarding how to operationally define it uniformly in different contexts". Moreover, Ellis and Sheen (2006, p. 575) argue that those problems are related to the fact that recasts can take different forms and perform several functions which are not necessarily corrective. It has also been controversial to clearly define recast because some researchers have stated that students can easily confuse it with positive evidence.

In that context, the present documental research aimed to analyze recast as NF in the foreign language classroom. For that purpose, first, a review to its definition will be provided. Secondly, different recast types will be discussed to, finally, present the main issues regarding recast effectiveness as NF according to the literature.

\section{APPROACHING THE DEFINITION OF RECAST}

In the present paper it is not intended to provide a unique concept of recast but to offer the definitions researchers have proposed through years for this type of implicit feedback to help the reader to get an understanding of this particular NF.

Some decades ago, Chaudron (1977) referred to recast as 'repetition with change'. Lyster and Ranta (1997) defined it as a reformulation of the learner's utterance minus the error(s). Later, Lyster (1998) added that recast is the teacher's implicit provision of a correct reformulation of all or part of a student's ill-formed utterance.

Sheen (2006, p. 365) defined recast as the teacher's partial or total reformulation of a student's utterance, containing at least one error within the context of a communicative activity in the language classroom. Then, Mousavi and Behjat (2014, p. 908) consider recast as an attempt to imitate the way real-life correction happens. According to Mousavi and Behjat, a recast is typically the way people in the street or in shops react to learners'errors, and it is generally how parents correct their children; in other words, recasts are an indirect and gentle way of giving feedback.

Recasts have been more frequently observed when single errors appear (Oliver, 1995, p. 471). An example of recast is observed in the following excerpt:

Student: She don't come to class everyday.

Teacher: She doesn't come to class every day.

Student: Yes, she doesn't come to class every day. 
It can be noticed that the student produces an ill-formed utterance and the teachers repeats it, but without the error (i.e., the teacher offers the expected production); then, the student notices it and teachers can know it because of the student's uptake. Another example of recast is presented in the following excerpt, taken from Perdomo (2008, p. 160):

T: "What has happened?"

S: "The boy has fell from the bicycle."

$T$ : "Ah, the boy has fallen from the bicycle."

S: "Yes, the boy has fallen from the bicycle."

In the previous excerpt, the recast was accompanied by an interjection to create a context for noticing to occur easily, as suggested by Anmar (2008). Those modifications in recast provision have led researchers to talk about different recast types which will be discussed in the next section.

\section{Types of recast}

Recast is among the most frequently studied corrective feedbacks and several types of recast have been reported and studied in the literature. It has been found to generate more ambiguity to recast and its effectiveness for L2 acquisition. However, readers need to know the different recast types because it let them to find important differences that might have led to controversial results in the literature.

There is not a unified criterion for recast characterization and classification; that is a good reason leading the author of the present paper to compile as many of them as possible, which are available at the moment in the literature and, in some cases, to offer some excerpts to illustrate them.

It is important to notice that the categories according to which recasts have been classified are not mutually exclusionary. In fact, the reader will notice that a recast can simultaneously be called after different names as a product of presenting more than one characteristic (e.g., segmented unstressed didactic recasts; whole declarative one correction recast). Those apparently slight differences might have important influence in noticing and hence, in the generation of learners' uptake. They also can make the difference when comparing to other NF types.

Lyster (1998, pp. 58-59) classified recasts into four types: 
- Isolated declarative: It provides confirmation of a learner's message by correctly reformulating all or part of the student's ill-formed utterance.

- Isolated interrogative: It seeks confirmation of the learner's message by either totally or partially reformulating the utterance with rising intonation and no additional meaning.

- Incorporated declarative: It provides additional information by incorporating the correct reformulation of all or part of the ill-formed utterance into a longer statement.

- Incorporated interrogative recast: It seeks additional information though the incorporation of the correct reformulation of all or part of a learner's utterance into a question. Hence, Lyster (1998, p. 59) highlights that maintaining its implicitness, recast serves as feedback for providing or seeking confirmation of the message as well as for providing or seeking additional information related to the message.

Fukuya and Zhang (2002) introduced another kind of recast they called pragmalinguistic recast. It is defined as the caretaker's (who may be a teacher, a native speaker or similar) reformulation of: "(a) an utterance that is grammatically inappropriate by changing the head act (and adding some hedges) or (b) a pragmatically appropriate but grammatically incorrect utterance by changing the linguistic part of the head act" (p. 7). The authors state that this recast concerns both the pragmatic appropriateness and linguistic accuracy of learner's utterance.

There is a framework for pragmalinguistic recast. This framework, according to the abovementioned authors, relies on two main features: pragmatic appropriateness and linguistic accuracy, defining four types of recast:

- Type I or no recast: If there is a correct usage and a correct form recast is not needed.

- Type II occurs when there is a correct usage, but an incorrect form is produced; in this case, the recast is just on the linguistic forms of request conventions. 
- Type III is provided when there is an incorrect usage, but the correct form is used; in this case, the feedback is performed by using one of the four target request conventions.

- Type IV occurs when there is an incorrect usage and incorrect form; the recast is done by using one of the four target request conventions (Fukuya\& Zhang, 2002, p. 8).

In terms of explicitness, Sheen (2006, p. 361) introduced the idea of implicit and explicit recasts, both later studied by Zhuo (2010). Ellis and Sheen (2006) have questioned the total implicitness of recasts as claimed by previous researchers. They argue that recasts used in some studies contain other elements such as special stress and repetition making the recast quite explicit. In this sense, Ellis and Sheen (2006, p. 583) suggest not considering recast as necessarily implicit feedback because its implicitness will rely on the linguistic signals encoding the recasts and ${ }_{2}$ as a consequence, a recast could be partially implicit or explicit.

As long as researchers have addressed their attention to study recasts as negative feedback, more definitions and classifications have arisen to characterize their role in language learning sets. For example, Farrokhi and Hassan (2012, p. 73) clearly differentiated two types: (a) Intensive recast (directed at a single structure and encouraged the treatment of recasts as an explicit feedback) and (b) Extensive recast (directed at different structures, and encouraged the treatment of recasts as an implicit feedback).

The study of recast from an operational perspective is quite complex like the language learning process itself. It is possible that the complexity is related to the multiple variables surrounding language learning and teaching. Nevertheless, some researchers still find recast to be very commonly used in the language classroom (e.g., Wai, 2004) and some other still find recast to be effective as negative feedback in certain contexts (e.g., Iwashita, 2010; Perdomo, 2008). It is also observed in the literature that some efforts are still been made to tests the assumed effectiveness in different environments.

Asari (2012, p. 19-20) presents a set of so called by Sheen (2006) recasts' characteristics, but those somehow happento be categories to identify recast types, because sometimes when presenting one of those characteristics makes the difference between a less noticeable and a more noticeable recast (as found by Sheen, 2006). That difference, at the 
same time, would affect recasts effectiveness. The following paragraphs show those categories and the recast types within those categories according to previous authors. It is important to remember that those categories are not excluding so that a recast can be classified after to more than one category.

According to the length, recast can be less than five morphemes recast (excerpt 1) and five or more morphemes recast (excerpt 2). Sheen (2006) also includes word/short phrase recasts and clause/long phrase recasts.

\section{Excerpt 1}

Student: She are in class.

Teacher: She is in class.

\section{Excerpt 2}

Student: She have never did it before.

Teacher: She has never done it before.

Following the segmentation criterion, recasts can be segmented and whole. The former highlights the error by separating it from the rest of the ill-formed utterance (Loewen\&Philp, 2006) (excerpt 3). The latter refers to recasts lacking segmentation of the students' utterance (excerpt 4).

\section{Excerpt 3}

Student: They were ready to go to the home.

Teacher: To go home

\section{Excerpt 4}

Student: They were ready to go to the home. Teacher: They were ready to go home.

The emphasis given by the speaker is another category for the differentiation of two recast types, namely: unstressed recast (excerpt 5), stressed recast (excerpt 6), cue plus recast (excerpt 7) and recast only. Stressed recast has been defined as that in which the illformed structure to be corrected receives an unusual stress, through pitch, additional pausing and emphasis. Besides, cue plus recast is recast provided with additional signals than tends to enhance its noticeability (Asari, 2012, p. 19).

\section{Excerpt 5}

Student: I do the homework the Tuesdays. Teacher:I do the homework on Tuesdays.

\section{Excerpt 6}

Student: I do the homework the Tuesdays. Teacher: I do the homework ON Tuesdays. (Capitals indicating stressed word)

\section{Excerpt 7}

Student: I do the homework the Tuesdays.

Teacher: Ah! On Tuesdays. 
The linguistic focus of the recast determines three main kinds: phonetics recast (also considered prosody recasts) (excerpt 8), vocabulary recast (excerpt 9), and grammar recast (excerpt 10).

\section{Excerpt 8}

Student: The ship ate too much grass (reading from a text including the word sheep)

Teacher: The sheep ate too much grass.

\section{Excerpt 9}

Student: I can do the dress by myself.

Teacher: I can make the dress by myself.

\section{Excerpt 10}

Student: I do the homework on Tuesdays usually.

Teacher: I usually do the homework on Tuesdays.

Intonation differentiates two main types of recast: declarative (excerpt 11) which is a recast provided with falling intonation as a declarative statement; and interrogative (excerpt 12), a recast provided with no other signal than interrogative intonation.

\section{Excerpt 11}

Student: They do their homework the Tuesdays.

Teacher: They do their homework on Tuesdays. (Falling intonation).

\section{Excerpt 12}

Student:They do their homework the Tuesdays.

Teacher: They do their homework on Tuesdays. (Raising intonation)

The number of corrections provided determines two types of recast: one correction recast (excerpt 13) two or more correction recasts (excerpt 14). The number of corrections refers to whether the teacher corrects one or more mistakes in the same sentence.

\section{Excerpt 13}

Student: I done my homework the Tuesdays. Teacher: I do my homework.

\section{Excerpt 14}

Student:I done my homework the Tuesdays. Teacher: I do my homework on Tuesdays.

Mohammad and Zoobinshid (2014) studied recast as single and multi-move recast. Multi-move recast entails more than one feedback move containing at least a single recast (Sheen, 2006); they include three clearly differentiated types: Corrective recast (excerpt 15), repeated recast (excerpt 16) and combination recast (excerpt 17).

\section{Excerpt 15}

Student: She don't follow the instructions. Teacher: She doesn't follow the instructions, you're right.

\section{Excerpt 16}

Student: She don't follow the instructions.

Teacher: She doesn't follow the instructions. She doesn't follow them. 


\section{Excerpt 17}

Student: I done my homework yesterday.

Teacher: You mean...I did my homework yesterday?

The scope is a category including two recasts: Isolated (excerpt 18) and incorporated (excerpt 19).Isolated recast is similar to segmented recast because it concentrates just on the ill formed structure, but it differs from one correction recast because the latter occurs when the sentence presents more than one error. Incorporated recast has been seen as incorporated interrogative and incorporated declarative, both characterized as very ambiguous recasts.

\section{Excerpt 18}

Student: I do the homework the Tuesdays. Teacher: on Tuesdays.

\section{Excerpt 19}

Student: I done my homework yesterday. Teacher: I did my homework yesterday. I can see you're very responsible.

According to the types of changes made by the person who provides the feedback, recasts can be: addition recast (excerpt 20), deletion recast (excerpt 21), substitution recast (excerpt 22), reordering recast (excerpt 23), combination recast (excerpt 24). As it can be observed, addition recasts are those that correct by adding something to the students utterance; substitution recasts change the non-target like form by substituting it for a proper one; reordering recasts consists of the grammatical reorganization of the utterance; and finally, combination recasts which include two or more of the previously mentioned recast types.

\section{Excerpt 20}

Student: I do my homework Tuesdays. Teacher: I do my homework on Tuesdays.

\section{Excerpt 22}

Student: I do my homework the Tuesdays. Teacher: I do my homework on Tuesdays.

\section{Excerpt 21}

Student: I do my homework on the Tuesdays.

Teacher: I do my homework on Tuesdays.

\section{Excerpt 23}

Student: I do my homework don't on

Tuesdays.

Teacher: I don't do my homework on

Tuesdays.

\section{Excerpt 24}

Student: I does my homework the Tuesdays and the Fridays.

Teacher: I do my homework on Tuesdays and Fridays. 
Depending on the existence of reduction during the correction, teachers can observe reduction recast (excerpt 25) and no reduction recast (excerpt 26). Observe that in the former there is shortening of the utterance whereas for the latter there is not.

\section{Excerpt 25}

Student: I does make my homework by the Tuesdays.

Teacher: I do my homework on Tuesdays.

\section{Excerpt 26}

Student: I does my homework the Tuesdays. Teacher: I do my homework on Tuesdays.

The context will also determine two varieties of recast. In this sense, recast can be didactic (excerpt 27) and conversational (excerpt 28). Didactic recasts have also been identified as explicit recasts (which again sounds quite ambiguous) and conversational recasts are referred to as implicit (Sheen \& Ellis, 2011, p. 5).

\section{Excerpt 27}

Student: I has done my homework. Teacher: I HAVE done my homework. (Capitals indicating emphasis).

\section{Excerpt 28}

Student: Shedon't follow instructions.

Teacher: She doesn't follow the instructions.

The different kinds of recast than can take place during oral interaction increases recast ambiguity and, therefore, it makes more complex its study. Researchers need to consider all the diverse recasts when comparing to other feedback types in order to measure effectiveness; they also should be very specific when describing the type of recast included in their studies for a better comparison and to get clearer conclusions. Teachers also need to take that into account when making decisions based on some finding reported in the literature. It is evident the need to start studying recast by comparing among its different types in order to study its effectiveness; in this sense, it would be possible to approach the most effective in specific contexts to then compare it to other feedback types.

\section{SOME ISSUES RELATED TO RECASTS' EFFECTIVENESS}

Some concerns have seemed to be related to recasts' effectiveness in the literature. The efficacy of recasts has been seen to depend, to some extent, on factors impacting their saliency and noticeability and thus, L2 learning outcomes; these factors are intonation, length, number of changes (Goo \& Mackey, 2013, p. 130), among other. It is difficult to 
draw a conclusion in terms of their effects because most of the studies do not provide enough sound empirical data to draw conclusions. However, by gathering the available information it is possible to generate hypotheses on the possible relationship between recasts and subjective and context factors present during the learning process. The present section is intended to approach some variables associated to the effectiveness of recasts as seen in the literature and to open paths for further research for those interested on recast effectiveness.

\section{Students' proficiency}

Proficiency is a construct found in the literature as related to recasts usefulness in the classroom. It has commonly been reported as related to feedback effectiveness (Sato, 2011, p. 15). Nicholas, Lightbow and Spada (2001, p. 752) claim that recasts can be effective if learners are in the position clear enough to choose among linguistic alternatives; that is, the more proficient the students are the more they benefit fromrecasts.

Tsybina, Girolamento, Weitzman and Greenberg (2006) observed a possible relationship between the two variables (recasts as negative feedback and learner's proficiency) in kids from a preschool context in an ESL classroom. Balcarcel (2006) found similar results in a university EFL classroom. Balcarcel recommends taking into account the students' level of proficiency of the language in order to teach what is appropriate and to provide the adequate negative feedback (Balcarcel, 2006, p. 362).

Anmar (2008) found that low proficiency students tended to benefit more from prompts than from recasts. Other researchers have included proficiency as a variable in their study of recasts effectiveness in the ESL classroom (e.g., Ammar\&Spada, 2006) and in laboratory settings (e.g, Mackey \&Philp, 1998; Philp 2003), but more empirical data is needed to draw conclusions on the topic.

Few experimental and quasi experimental studies have considered the variable of previous knowledge as an indicator of proficiency related to recasts. An example of those studies can be found in Perdomo (2008). She found a statistically significant interaction between previous knowledge on the language and feedback type (recast), that interaction would mean that recasts tend to benefit more proficient students (Perdomo, 2008, p. 163), as previously proposed by Nicholas, Light bow and Spada (2001). 
Other researchers have also either directly or indirectly addressed the issue (e.g., Mackey \&Philp, 1998; and Ammar\&Spada, 2006). Nevertheless, recasts as well as other feedback types have not been studied enough in terms of their relationships to learners' factors such as previous knowledge of the to-be-learned language. More research is needed to properly study the observed trend that high proficiency students benefit more from recasts and to compare the effectiveness of recast and other forms of implicit and explicit NF for high proficiency learners.

\section{Student's attitude and other affective variables}

Students' attitudes towards the language, the task, the interlocutor, the error and error correction, among others, might have an influence on the effectiveness of the received feedback. Few researchers have directly focused on learner's factors influence on recast effectiveness. As Ellis and Sheen (2006, p. 591) posit, it is also possible that other individual learner differences factors such as language aptitude, personality, general motivation and attitudes towards correction will influence NF effectiveness by affecting learner's receptivity. However, the effect of those factors has scarcely been investigated.

Morris and Tarrone (2003) found that when there are negative feelings addressing the interlocutor those feelings seem to interfere in the appropriated perception of recasts (Morris \&Tarrone, 2003, p. 325). This is another variable associated to recasts and other negative feedback types, which has scarcely been studied. Kartchava and Ammar (2014) investigated about the role of students' beliefs as mediators of noticing NF in the language classroom; they included recasts compared to prompts and a combination of recast-prompt. They found four common beliefs, but none of them impacted learners' outcomes even when two of them mediated noticeability of recasts (Kartchava\&Ammar, 2014, p. 86).

In terms of motivation, there is a lack of evidence. Little is known about the relationship between it and recasts effectiveness. Regarding this variable, Sharifi and Amiri (2014) compared the effects of recasts and prompts on EFL learners' autonomy and motivation. They found that both increased learners' autonomy, but none showed effects for motivation.

Anxiety has also shown to be related to recasts effectiveness in the language classroom. Rassaei (2015, p. 98) found high anxiety students to benefit significantly more 
from recasts whereas low anxiety learners benefit more from metalinguistic feedback. There are not many papers on this vein so far; hence, this is a chance for researchers to conduct studies to answer questions on the issue.

\section{Recasts explicitness or saliency and its relationship to noticing}

Sato (2011) explains that explicitness of recast will influence whether learners notice the provided feedback and hence its effectiveness. Recasts have been recognized in the literature as implicit negative feedback, but Ellis and Sheen (2006) present a very detailed discussion about the implicitness or explicitness of recast and conclude that they cannot purely be seen as an implicit form of feedback but also as a relatively explicit one.

Recasts have been seen as less noticeable than other feedback types, for example, prompts. Authors have affirmed that feedback saliency has an influence on its effectiveness (even when there are not enough empirical data to properly support that claim). Nevertheless, Philp (2003) indicates that students can be taught to develop the ability to notice recasts; conversely, to our knowledge, no study has been reported on the issue.

Some authors have discussed about the saliency of recasts and how it could be related to students' uptake and repair and to recasts effectiveness for learning. Recasts saliency have been related to the length of the utterance (Eggi, 2007). Sheen (2006, p. 361) also states that the length of recasts as well as the linguistic focus (i.e., pronunciation, grammar), types of change (i.e., substitution, addition), mode (i.e., declarative, interrogative), the use of reduction (i.e., complete or partial recasts), and the number of changes (one or multiple) influence the explicitness of recasts.

Noticing in language learning is mainly the idea that if learners focus on the form and meaning of certain language structures in input, this will contribute to the internalization of the rule (Batstone, 1996). Swain (1998) listed three main types of noticing in terms of what is noticed. Then, noticing may be: (1) related to the form of the input, (2) noticing own interlanguage deficiencies, and (3) noticing the gap between the interlanguage and the target language.

Feedback explicitness or saliency has directly been related to noticing and it has mainly been assessed taking into account students' uptake. The more uptake the students produce, the most noticeable the feedback is considered. Asari (2012) names some other 
recasts features such as intonation, stress, segmentation and the number of changes that might be associated to noticing. Student's motivation might be also added to the list of factors related to noticing.

More research should be conducted to precisely determine how those features take place in different interaction settings, how they influence recasts salience and effectiveness, andhow closely related are recasts and noticing language structures in ESL and EFL settings.

\section{Teaching and learning context}

The context where the feedback is being assessed might influence the results. In other words, different outcomes have been found for different languages teaching and learning contexts (e.g., EFL, ESL, French immersion classes). Recasts have also been different among varied educational level contexts (e.g., preschool, high schools, college) and studies designs or methodological contexts (e.g., descriptive studies, experimental designs). The set of the research (e.g., classroom, laboratory) might also has an influence on recasts noticing and, hence, on its effectiveness. The major criticism that relies on the effectiveness of recast is related to results in laboratory studies which are not generalizable to real life teaching environments in different cultures.

In this sense, further research is expected to compare the effectiveness of recast in different settings (especially in the classroom) in order to clarify whether those variables have any influence on feedback effectiveness.

\section{To-be-learned features}

It is possible that complexity, frequency of use, saliency of grammatical structures, among other features regarding the corrected item might influence the effectiveness of recast. Nonetheless, there is not much research about it. Among the studies that can be mentioned here is Saito (2013) who investigated the way that recast can promote L2 pronunciation development of specific sounds in a quite complex study including developmental stages of English acquisition of the sound and four other variables (i.e., amount of recasts and repairs, initial pronunciation levels and explicit articulatory knowledge). According to Saito, the effectiveness of recast seems to be related to the 
amount of recast (another unexplored variable related to its effectiveness) and repairs and initial pronunciation levels.

Some studies have focused the study of recasts with specific grammatical forms such as perfect present (Perdomo, 2008), and plurals and locatives (Yilmaz, 2012 and 2013), for instance. However, there is no sound empirical evidence either to make judgments about the effectiveness of recast for any of those items.

\section{RECAST EFFECTIVENESS IN THE LANGUAGE CLASSROOM}

It is important to highlight that a problem that authors face when judging the effectiveness of recast relies on recast itself because of its ambiguous nature and the wide range of recasts types. There are two main trends of researchers focused on the study of recasts an NF: On the one hand, those who claim that recast effectiveness might have been overestimated (e.g., Lyster\&Ranta, 2013), and on the other hand, the ones who have taken a stand for recasts as very effective NF (e.g., Goo \& Mackey, 2013). This controversy generates a fertile soil for other investigators who want to study recasts effectiveness because both trends offer interesting statements and hypotheses to be tested. For the purpose of the present paper, the author does not pretend to offer an analysis of the effectiveness of recast deriving from the aforementioned controversy but to open a discussion about recasts effectiveness research in relation to other factors or variables.

Recasts are particularly important as they are of considerable theoretical interest to SLA researchers and because of their pedagogical significance (Sheen, 2008). They have been described as time-saving, less threatening for students' confidence and positive for maintaining the focus on meaning (Loewen\&Philp, 2006, p. 551). Research findings have suggested theoretical explanations to how recasts in particular may be efficient for language learning. Asari (2012) indicates that reasons frequently cited include: (a) Implicitness, (b) learner-centeredness, (c) unobtrusiveness, and (d) the dual function of positive and negative evidence provided by recasts.

However, results from diverse studies have presented controversial findings and have challenged the effectiveness of recast in the language classroom. The main problem for 
defining the effectiveness of recast is that authors have operationalized them differently, for instance, in terms of its explicitness (Sheen, 2006) and learners' uptake.

The effectiveness of recast has been assessed by doing some research following experimental, quasi experimental, and descriptive designs focused on the learning of some grammatical forms and the amount of noticing and uptake following recasts when compared to other feedback types (i.e., students' response). In addition to the study of recasts' effectiveness, also several descriptive studies have reinforced the idea of recasts' importance by reporting the frequency of use in teacher-students interaction and peers interaction in the classroom; still, the fact that recasts are very commonly used should not be interpreted as they are common because of helpfulness.

In terms of its effectiveness, Nicholas Lightbown and Spada (2001) found recast to be the most effective when the learner clearly understands that the recast is a reaction to the accuracy of the form, not the content, of the utterance (Nicholas, et al. 2001); nonetheless, this effectiveness has been questioned by some authors. Sheen (2006) and other researchers have found a number of difficulties that researchers may face when studying recasts, they are listed below:

1. Recasts do not constitute a homogeneous construct because they exist in a variety of forms.

2. Recasts are also functionally different (i.e., they can serve both communicative and didactic functions).

3. The challenged implicitness of recast also adds some complexity to its study; in this vein, Sato (2011) adds that the explicitness of recast is largely affected by how a learner interprets the illocutionary force of any given recast.

4. The impossibility for saying with any certainty whether recasts constitute a source of negative evidence (as commonly assumed) or afford only positive evidence, as this will depend on the learner's orientation to the interaction.

5. Learner's difficulty in perceiving the corrective force of recast because of its multiple functions is another source of controversy when studying recast as well as uncertainty of the roles of uptake and repair. 
6. The type and number of changes made in the recast and its effectiveness to result in uptake with repair or facilitate acquisition is also a controversial issue when assessing the role of recasts in language learning.

In the literature there is a considerable amount of research on negative feedback, particularly on recasts. Contrariwise, when reviewing research types, designs and settings, they are varied and there has not been a sound systematic study of specific matters related to recasts. Hence, there is still a long way to go in order to draw strong conclusions. In fact, Sato (2011) states that the difficulty for researchers to perform solid meta analyses relies on the lack of experimental and quasi experimental research providing statistical analyses and measures useful to calculate effects size.

\section{FINAL COMMENTS AND CONCLUSIONS}

The first attempts in the study of negative feedback include an emblematic descriptive study labeling the kinds of feedback occurring in the language classroom. Since Lyster and Ranta (1997), the literature shows recast to be one of the most commonly used negative feedback type.

After reviewing more than two decades of research, many questions regarding its use still need to be answered. Among the remaining doubts on recasts, one may mention the lack of studies on the affective variables such as students' anxiety, students' attitude towards negative feedback and towards recasts themselves which might be related to feedback effectiveness. That is, researchers have not explored enough on learners' perception of recasts and how it might affect its effectiveness and they have mostly studied recasts in terms of uptake and repair. Also students' attitude towards the interlocutor has shown to influence recasts effects on learners, but more research should be conducted to draw conclusions about it.

In terms of effectiveness, a number of studies have shown that benefits of recasts for L2 development depend on learner proficiency and feature of language production (e.g., pronunciation, syntax), among other. Recasts explicitness is a recent topic regarding that kind of feedback in the foreign language classroom; findings suggest that it has an 
influence on recasts benefits for language learners. Nevertheless, few researchers have addressed this variable as well as the salience of negative evidence of recasts. Further empirical data for tasks effects and the conditions that enhance the benefits of recast in all its forms is also needed. Even when Zhaohong (2002) identify some possible conditions, no studies have been found to deeply study them and then, more research should be conducted to study their effect on learning when using recasts.

Noticing is probably one of recasts greater weaknesses. More research controlling this variable is needed to draw a more consistent conclusion because available empirical research is not enough. There are yet other controversial features of recast and there are authors who have found it equal or less effective than explicit negative feedback or other forms of feedback.

Recast has definitively proven to be very frequent in a variety of language teaching and learning settings; that is another reason to invite teachers and researcher to investigate more about it.

Even when recast effectiveness is still challenged by some researchers, some others prefer and recommend recasts because of some pedagogical benefits. Among those benefits it is possible to list that they are time saving when correcting, they do not seem to affect students' confidence and their interference on the flow of communication is very low.

Studies regarding recast effectiveness should be carefully reviewed in order to identify possible bias (e.g., the to-be-learned structure, nature of feedback compared or learners' age, type of recast used in the study). In other words, readers need to be careful and avoid generalizations of conclusions after a couple of published manuscripts in specific learning environments and with a certain number of interfering variables. For example, it is wrong to think that recast works for all grammatical structures just because they find a study where recast seems to be as effective as other feedback for the learning of a specific grammatical structure; readers need to remember that it might not be the same for other more complex ones.

Teachers and researchers should also take into account that frequency does not imply efficiency; in other words, the fact that recast is very common in the language classroom does not imply that it is the more effective feedback type in all cases. 
With the present review the author does not completely deny the effectiveness of recast (one might think that it might be useful combined with other feedback types; it still has to be proven) but she invites researchers to continue testing it in diverse language teaching and learning sets with the purpose of clarifying remaining controversies related to recasts and the effectiveness of other negative feedback types. Before using or recommending recast, teachers should be aware of some factors that might affect its effectiveness: (1) task type, (2) students proficiency and age, (3) students affective factors (e.g, anxiety, motivation to learn the language, and attitude towards the interlocutor, among others), (4) feedback saliency, (5) presence of positive evidence, and (6) recasts ambiguity, among other.

\section{REFERENCES}

Ammar, A.\&Spada, N. (2006). One size fits all? Recasts, prompts, and L2 learning.Studies in Second Language Acquisition, 28, 543-574.

Ammar, A. (2008). Prompts and recasts: differential effects on second language morphosyntax. Language Teaching Research April, 12 (2), 183-210.

Asari, Y. (2012).Types of Recasts and Learners' Uptake.Dialogue, 10,1-20.

Balcarcel, G. (2006). La corrección del error en clase de inglés como lengua extranjera. LETRAS, 48 (73), 349-363.

Batstone, R. (1996). Key Concepts in ELT: Noticing. ELT Journal, 50 (3), 273-280.

Chaudron, C. (1977). A description model of discourse in the corrective treatment of learners' errors.Language Learning, 27, 29-46.

Eggi, T. (2007). Interpreting recasts as linguistic evidence: The role of linguistic target, length and degree of change. Studies in Second Language Acquisition, 29 (4), 511-537.

Ellis, R. \& Sheen, Y. (2006).Reexamining the role of Recasts in second Language acquisition. Studies in Second Language Acquisition, 28, 575-600.

Farrokhi, F. \& Hassan, M. (2012). The Effects of Planned Focus on Form on Iranian EFL Learners' Oral Accuracy. World Journal of Education, 2, (1), 70-81.

Fukuya, Y. \& Zhang, Y. (2002).Effects of recasts on EFL learners' acquisition of pragmalinguistic conventions of request.Second Language Studies, 21 (1), 1-47.

Goo, J. \& Mackey, A. (2013).The case against the case against recast.Studies in Second Language Acquisition, 35, 127- 165 . 
Iwashita, N. (2010). The effect of intensive recast treatments on the long-term development of less salient structures in Japanese as a foreign language.NihongoKyoihu, 146, 18-33.

Kartchava, E. \&Ammar, A. (2014).Learner's beliefs as mediators of what is noticed and learned in the language classroom.TESOL Quarterly, 48 (1), 86-109.

Loewen, S. \&Philp, J. (2006). Recasts in the adult English L2 classroom: characteristics, explicitness, and effectiveness. The Modern Language Journal, 90(4) 536-556.

Lyster, R (1998). Recasts, repetition and ambiguity in L2 classroom discourse.Studies in Second Language Acquisition, 20 (1), 51-81.

Lyster, R. \&Ranta, L. (1997).Corrective feedback and learner uptake.Studies in Second Language Acquisition, 19 (1), 37-66.

Lyster, R. \&Ranta, L. (2013). Counterpoint piece: the case for variety in corrective feedback research. Studies in Second Language Acquisition, 35 (1), 167-184.

Mackey, A., \&Philp, J. (1998). Recasts, interaction and interlanguage development: Are responses red herrings? Modern Language Journal, 82, 338-356.

Mohammad, N. \&Zoobinshid, A. (2014). The Role of Structure Novelty on the Efficacy of Recasts: An Experimental Study on Iranian Upper-intermediate EFL students. Theory and Practice in Language Studies, 4 (5), 949-957.

Morris, F. \&Tarone, E. (2003).Impact of classroom Dynamics on the effectiveness of Recasts in Second Language acquisition.Language Learning, 53 (2) 325-368.

Mousavi, S. \&Behjat, F. (2014).Overt-correction vs. Recasts and Grammar Performance of Iranian Male Learners of English.Journal of Language Teaching and Research, 5 (4), 906-917.

Nicholas, H.; Lightbow, P. \&Spada, N. (2001).Recast as feedback to language learners.Language Learning, 5 (4), 719-758.

Oliver, R. (1995). Negative feedback in Child NS-NNS conversation.Studies in Second Language Acquisition 17, (4), 459-481.

Panova, I. \&Lyster, R. (2002).Patterns of corrective feedback and uptake in an adult ESL Classroom.TESOL Quarterly, 36 (4), 573-595.

Perdomo, B. (2008). Effectiveness of recast in the teaching of EFL.The Asian EFL Journal, $10(2), 155-166$.

Philp, J. (2003). Constrains of "noticing the gap": Nonnative speakers' noticing of recasts in NS-NNS interaction.Studies in Second Language Acquisition, 25 (1), 99-126.

Rassaei, E. (2015). Oral corrective feedback, foreign language anxiety and L2 development.System, 49, 98-109. 
Rassaei, E. Moinzadeh, A. \&Youhannaee, M. (2012a).Recasts, Modified Output and L2 Development: A Case of Persian EFL Learners. English Language and Literature Studies, 2 (1), 100-111.

Rassaei, E. Moinzadeh, A. \&Youhannaee, M. (2012b).The effect of corrective feedback on the acquisition of implicit and explicit L2 knowledge.The Journal of Language Teaching and Learning, 2 (1), 59-75.

Saito, K. (2013). The Acquisitional Value of Recasts in Instructed Second Language Speech Learning: Teaching the Perception and Production of English / $/$ / to Adult Japanese Learners.Language Learning, 63(3), 499-529.

Sato, M. (2011). Constitution of form-orientation: Contributions of context and explicit knowledge to learning from recasts. The Canadian Journal of Applied Linguistics (14), $1-28$

Sharifi, N. \&Amiri, B. (2014).The Comparative Impact of Recast and Prompt on EFL Learners' Autonomy and Motivation. Procedia - Social and Behavioral Sciences, 98, 1754-1761.

Sheen, Y. \&Ellis , R.( 2011 ). Corrective feedback in language teaching.In E. Hinkel (Ed.), Handbook of research in second language teaching and learning (Vol. 2, pp. 593 610). London: Routledge .

Sheen, Y. (2006). Exploring the relationship between characteristics of recasts and learner uptake.Language Teaching Research, 8 (4), 361-392.

Sheen, Y. (2008). Recast, language anxiety, modified output and L2 learning. Language Learning, 58 (4), 835-874.

Swain, M. (1998). Focus on form through conscious reflection. In C. Doughty \& J. Williams (Eds.), Focus on form in classroom second language acquisition (pp. 64-81). Cambridge: Cambridge University Press.

Tysibina, I.; Girolamento, L.; Weitzman, E. \& Greenberg, J. (2006). Recasts used with preschoolers learning English as their second language. Early Childhood Educational Journal, 34(2), 177-185.

Wai K., T. (2004). Feedback and uptake in Teacher-student interaction: an analysis of 18 English lessons in Hong Kong Secondary Classrooms. RELC Journal, 35 (2), 187-209.

Yilmaz, Y. (2012). The relative effects of explicit correction and recasts on two target structures via two communication modes.Language Learning, 62 (4), 1134-1169.

Yilmaz, Y. (2013). Explicit and implicit feedback: the role of working memory capacity and language analytic ability. Applied Linguistics 34 (3), 344-368. 
Zhaohong, H. (2002). A study of the impact of Recasts on tense consistency in L2 Output.TESOL QUARTERLY, 36(4), 543-572.

Zhuo, C. (2010). Explicit Recast, Implicit Recast and the Acquisition of English Noun Plural: A Comparative Study. ChineseJournal of AppliedLinguistics, 33 (6), 55-70. 